\section{Effectiveness of influenza vaccine in TNF inhibitors treated patients: comment on the article by Burmester et al}

Tumour necrosis factor- $\alpha$ inhibitors (TNFi) are immunosuppressive therapies that are known to increase infectious risk. Indeed, patients affected by TNFi requiring conditions are at higher risk of influenza compared with healthy controls. ${ }^{1}$ Furthermore, mildly reduced seroconversion rate after influenza vaccination had been reported in TNFi-treated patients. ${ }^{2}$ Nonetheless, the immune response is considered large enough to recommend influenza vaccination in all patients affected by rheumatoid arthritis, regardless of treatment. ${ }^{3}$ However, there are data showing that patients are not being vaccinated as recommended. ${ }^{4}$ In addition, given that subjects with autoimmune conditions treated with TNFi are at higher risk for influenza, ${ }^{1}$ the exact number needed to vaccinate (NNV) for this condition is still unknown.

$\mathrm{NNV}$ is the required number of patients receiving vaccination to prevent one case of a given infectious disease. NNV is the inverse of the absolute risk reduction (ARR), which is calculated as following: Control Event Rate (CER) - Experimental Event Rate (EER). For example, influenza vaccination reduced influenza rate in 71 221 healthy adults from $2.3 \%$ in individuals without vaccination $(\mathrm{CER}=0.023)$ to $0.9 \%$ in vaccinated individuals $(\mathrm{EER}=0.009){ }^{5}$ The NNV in this scenario is $71(\mathrm{NNV}=1 / \mathrm{ARR}, \mathrm{ARR}=0.023-$ 0.009), namely 71 healthy adults need to be vaccinated to prevent one of them experiencing influenza. In addition, the NNV gives us the opportunity to calculate the cost for preventing one case of influenza. Assuming a cost per vaccine from $\$ 20$ to $\$ 40$, the costs to prevent a case of clinical influenza in healthy controls would range from $\$ 1420$ to $\$ 2840$.

In this recent analysis on 15132 patients exposed to adalimumab, Burmester and colleagues reported influenza-related adverse
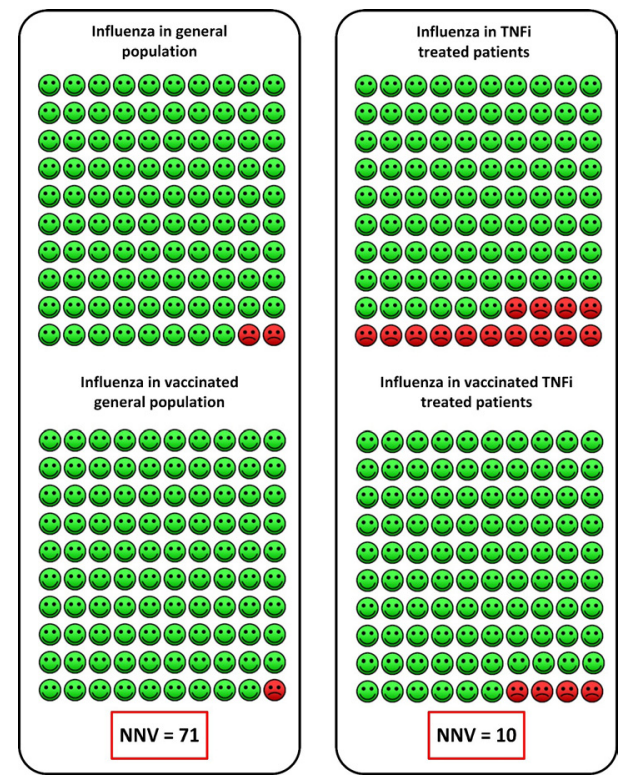

Figure 1 NNV for influenza in the general population and in patients treated with TNFi. NNV, number needed to vaccinate; TNFi, tumour necrosis factor- $\alpha$ inhibitors. events in 55 of 382 not-vaccinated patients $(C E R=0.14)$ and in 8 of 179 vaccinated patients $(\mathrm{EER}=0.04){ }^{6}$ In this population (mean age 53.5 years, predominantly white women), the NNV of influenza vaccines was $10(\mathrm{NNV}=1 / \mathrm{ARR}, \mathrm{ARR}=0.144-0.045)$ and preventing a case of influenza would cost approximately from $\$ 200$ to $\$ 400$, which is largely lower when compared with healthy controls' costs. Thus, when estimating the effectiveness of vaccinations, clinicians should always include the calculation of the $\mathrm{NNV}$ and not only the calculation of risk ratio (RR), which might be misleading. For example, the RRs of influenza vaccination in healthy individuals ( $2.3 \%$ to $0.9 \%$, RR $0.41,95 \%$ CI 0.36 to 0.47 ) and patients with rheumatoid arthritis treated with TNFi $(14.4 \%$ to $4.5 \%$, RR $0.31,95 \% \mathrm{CI} 0.15$ to 0.64 ) are similar, while there is a large difference between NNVs (71 vs 10) (figure 1). This difference is due to a greater absolute risk for influenza in the latter group.

The present analysis provides further evidences on the effectiveness of influenza vaccination in patients affected by rheumatoid arthritis receiving treatment with TNFi and should represent a callto-action for all rheumatologists to consider vaccination in such patients.

Giovanni Adami, ${ }^{\oplus}$ Angelo Fassio, Giovanni Orsolini, Alessandro Giollo, Davide Gatti, Maurizio Rossini

Rheumatology Unit, University of Verona, Verona, Italy

Correspondence to Dr Giovanni Adami, Rheumatology Unit, University of Verona, Verona 37135, Italy; adami.g@yahoo.com

Handling editor Josef S Smolen

Contributors All authors contributed equally to the design of the study and write-up of the letter.

Competing interests None declared.

Provenance and peer review Not commissioned; internally peer reviewed.

(C) Author(s) (or their employer(s)) 2019. No commercial re-use. See rights and permissions. Published by BMJ.

\section{(A) Check for updates}

To cite Adami G, Fassio A, Orsolini G, et al. Ann Rheum Dis Epub ahead of print: [please include Day Month Year]. doi:10.1136/annrheumdis-2019-215174

Received 2 February 2019

Accepted 6 February 2019

Ann Rheum Dis 2019;0:1. doi:10.1136/annrheumdis-2019-215174

\section{REFERENCES}

1 Hak E, Nordin J, Wei F, et al. Influence of high-risk medical conditions on the effectiveness of influenza vaccination among elderly members of 3 large managed-care organizations. Clin Infect Dis 2002;35:370-7.

2 Kobie JJ, Zheng B, Bryk P, et al. Decreased influenza-specific B cell responses in rheumatoid arthritis patients treated with anti-tumor necrosis factor. Arthritis Res Ther 2011;13.

3 van Assen S, Elkayam O, Agmon-Levin N, et al. Vaccination in adult patients with auto-immune inflammatory rheumatic diseases: a systematic literature review for the European League against rheumatism evidence-based recommendations for vaccination in adult patients with auto-immune inflammatory rheumatic diseases. Autoimmun Rev 2011;10:341-52.

4 Curtis JR, Arora T, Narongroeknawin P, et al. The delivery of evidence-based preventive care for older Americans with arthritis. Arthritis Res Ther 2010;12.

5 Demicheli V, Jefferson T, Ferroni E, et al. Vaccines for preventing influenza in healthy adults. Cochrane Database Syst Rev 2018;2.

6 Burmester GR, Landewé R, Genovese MC, et al. Adalimumab long-term safety: infections, vaccination response and pregnancy outcomes in patients with rheumatoid arthritis. Ann Rheum Dis 2017;76:414-7. 